\title{
As campanhas contra o Influenza e seu caráter educacional: análise do material produzido em 2016
}

\author{
Campaigns against Influenza and its educational character: analysis of \\ the material produced in 2016
}

\section{Campañas contra la Influenza y su carácter educativo: análisis del material producido en 2016}

Giovana Marcelino Stilben de Souza ${ }^{1, a}$

giovanamarcelino@gmail.com | https://orcid.org/oooo-0003-2760-2039

Mariana Peres Rodrigues ${ }^{1, a}$

mari.peresrodrigues@hotmail.com | https://orcid.org/o0oo-0003-0543-1195

Matheus Marques da Silva Santos ${ }^{1, a}$

matheusmarkesantos@hotmail.com | https://orcid.org/oooo-0003-2300-930X

Leda Márcia Araújo Bento ${ }^{1, b}$

leda.bento@uniderp.com.br | https://orcid.org/0000-0003-2055-2403

Antonio Sales $^{1, c}$

professorsales1@gmail.com | http://orcid.org/oooo-0001-5515-6625

${ }^{1}$ Universidade Anhanguera Uniderp. Campo Grande, MS, Brasil.

a Graduando em Medicina pela Universidade Anhanguera Uniderp.

${ }^{\text {b }}$ Doutorado em Farmacologia pela Universidade Estadual de Campinas.

c Doutorado em Educação pela Universidade Federal do Mato Grosso do Sul.

\section{RESUMO}

O avanço das complicações desenvolvidas pelas doenças é notável, tanto no número crescente de mortes quanto no de internações, sendo o vírus Influenza um dos representantes dos causadores desses males. Dessa forma, buscam-se maneiras eficazes de prevenir doenças como a gripe; entre tais medidas estão lavar as mãos com frequência, não compartilhar determinados objetos e, como ação mais eficaz, a vacinação. Por tal motivo, o trabalho em que se baseia este artigo tem o objetivo de analisar os tipos de conteúdo presentes em materiais elaborados pelo Ministério da Saúde no Brasil para campanha de vacinação contra a gripe no ano de 2016. A pesquisa faz uso das categorias de análise prescritas por Antoni Zabala acerca das práticas de ensino e aprendizagem. No decorrer da análise foi observado que o modo como o material foi elaborado em 2016 e a forma como foram dispostos os conteúdos, imagéticos e textuais, podem influenciar a eficácia das campanhas de vacinação.

Palavras-chave: Prevenção; Eficácia; Vacinação; Ministério da Saúde; Influenza. 


\title{
ABSTRACT
}

The advance on complications developed by diseases is notable, both in the growing number of deaths and in the number of hospitalizations, and the Influenza virus is one of the causes of these diseases. Thus, effective ways of preventing diseases such as the flu are sought; such measures include washing frequently the hands, do not sharing certain objects and, as the most effective action, vaccination. For this reason, the study on which this article is based aims to analyze the types of content found in materials prepared by the Ministry of Health in Brazil for the flu vaccination campaign developed in the year 2016. The research makes use of the analysis categories prescribed by Antoni Zabala about teaching and learning practices. During the analysis, it was observed that the way of preparing the material in 2016 and the way of arranging the contents, both imagery and text, can influence the effectiveness of vaccination campaigns.

Keywords: Prevention; Effectiveness; Vaccination; Ministry of Health; Influenza.

\section{RESUMEN}

Es notable el aumento de las complicaciones que las enfermedades provocan, tanto en el creciente número de muertes como en el número de casos que exigen hospitalización, siendo el virus de la Influenza una de las causas de esas enfermedades. Por eso se buscan formas eficaces de prevenir enfermedades como la gripe; tales medidas incluyen lavar las manos con frecuencia, no compartir ciertos objetos y, como acción más eficaz, la vacunación. Por esta razón, el estudio que fundamenta este artículo tiene como objetivo analizar los tipos de contenido presentes en los materiales preparados por el Ministerio de Salud en Brasil para la campaña de vacunación contra la influenza desarrollada en lo año 2016. La investigación hace uso de las categorías de análisis prescritas por Antoni Zabala sobre prácticas de enseñanza y aprendizaje. Durante el análisis, se observó que la forma en que se preparó el material en y la forma en que se organizaron los contenidos, tanto las imágenes como el texto, pueden influir en la efectividad de las campañas de vacunación.

Palabras clave: Prevención; Efectividad; Vacunación; Ministerio de Salud; Influenza.

\begin{abstract}
Contribuição dos autores: Silva Santos e Mariana Peres Rodrigues. Matheus Marques da Silva Santos e Mariana Peres Rodrigues.

Declaração de conflito de interesses: não há.

Fontes de financiamento: Bolsa PIBIC fornecida pelo CNPq.

Considerações éticas: não há.
\end{abstract}

Concepção e desenho do estudo: Giovana Marcelino Stilben de Souza, Leda Márcia Araújo Bento e Antônio Sales. Aquisição, análise ou interpretação dos dados: Giovana Marcelino Stilben de Souza e Antônio Sales.

Redação do manuscrito: Giovana Marcelino Stilben de Souza, Leda Márcia Araújo Bento, Antônio Sales, Matheus Marques da

Revisão crítica do conteúdo intelectual: Giovana Marcelino Stilben de Souza, Leda Márcia Araújo Bento, Antônio Sales,

Agradecimentos/Contribuições adicionais: não há.

Histórico do artigo: submetido: 11 fev. 2020 | aceito: 23 dez. 2020 | publicado: 22 mar. 2021.

Apresentação anterior: não há.

Licença CC BY-NC atribuição não comercial. Com essa licença é permitido acessar, baixar (download), copiar, imprimir, compartilhar, reutilizar e distribuir os artigos, desde que para uso não comercial e com a citação da fonte, conferindo os devidos créditos de autoria e menção à Reciis. Nesses casos, nenhuma permissão é necessária por parte dos autores ou dos editores. 


\section{INTRODUÇÃO}

A vacina tem a sua história que remonta ao século XVIII, quando o médico Edward Jenner (1749-1823) descobriu que, caso o pus oriundo das vacas com a doença cowpox (conhecida como 'varíola bovina') fosse inoculado em uma pessoa saudável, essa seria imunizada contra aquela doença, levando a uma sintomatologia mais branda (FIOCRUZ, 2010). De tal modo, hoje em dia a imunização é importante aliada na prevenção das doenças e é o fator principal para evitar novos surtos, diminuindo sua incidência e mortalidade e, em alguns casos, até mesmo levando à erradicação (GILIO, 2017).

Porém, não é de hoje que sua eficiência é questionada. Por exemplo, no ano de 1904, o Rio de Janeiro se encontrava com diversos problemas urbanos e entre eles um dos mais preocupantes era a proliferação de doenças, tais como sarampo, difteria, febre amarela e varíola, gerando os surtos dessas patologias pela cidade (RIO DE JANEIRO, 2006). Assim, no dia 31 de outubro de 1904 foi aprovada a Lei $\mathrm{n}^{0} 1261$ que decretava obrigatória a vacinação contra varíola em todo território nacional (BRASIL, 1904). Essa ficou conhecida popularmente como Lei da Vacinação Obrigatória e conduziu para as ruas a população que, enfurecida, enfrentou as autoridades e transformou bairros em praças de guerra com o saldo de trinta mortos e centenas de feridos, caracterizando "o maior motim da história do Rio de Janeiro" (SOUZA, 2006). A grande rebelião recebeu o nome de 'Revolta da Vacina' e teve seu motivo atribuído à confusão da população com a revolta contra as demolições das habitações populares; porém, ainda assim, levou à suspensão da obrigatoriedade da imunização no mesmo ano (RIO DE JANEIRO, 2006).

Por conseguinte, tais questionamentos sobre as imunizações seguem até hoje e são até motivo de estudos de seus padrões. Um estudo nos Estados Unidos da América feito durante o período de 1995 a 2001 se propôs a avaliar os dados obtidos por meio do National Immunization Survey, armazenados em um banco de dados sobre as imunizações do país (SMITH; CHU; BARKER, 2004). Uma amostra probabilística nacionalmente representativa de crianças de 19 a 35 meses de idade foi coletada anualmente entre 1995 e 2001.

Atendendo a esses critérios, ao todo foram selecionadas 151.720 crianças no período mencionado, sendo elas classificadas em 'imunizadas', 'subimunizadas' e 'não imunizadas'. Ao se analisarem as características de cada grupo, notou-se que as que se enquadravam no segundo grupo vivem sob condições socioeconômicas e educacionais consideradas adversas, pois são filhos e filhas de mães mais jovens, solteiras, com baixa escolaridade e residentes em moradias próximas à linha de pobreza nos grandes centros urbanos. Por outro lado, as que fazem parte dos agrupamentos conceituados como 'não imunizadas' eram predominantemente meninos, filhos de mães casadas, com alto nível de escolaridade que residem em habitações com renda acima da média do país, contando com grande acesso aos meios de comunicação. Desse modo, foi observado que entre os responsáveis das crianças 'não imunizadas' havia uma preocupação com possíveis efeitos ocultos da vacina, como o autismo, além de motivações filosóficas e religiosas, fato não observado nos responsáveis pelo grupo ‘subimunizadas'. Tais fatos levam à conclusão de que há diferentes razões para a subimunização dentro de uma sociedade, necessitando de diferentes ações para sua erradicação (SMITH; CHU; BARKER, 2004).

Os vírus são agentes capazes de causar epidemias anuais frequentes, podendo levar também a pandemias. Um exemplo é o agente causador da gripe, a Influenza, causando epidemias que podem atingir todas as faixas etárias (FORLEO-NETO et al., 2003). Mesmo atingindo diferentes populações, alguns indivíduos podem ser mais gravemente acometidos: os extremos de idades (crianças abaixo de quatro anos e pessoas acima de 65 anos), gestantes (principalmente nos dois últimos trimestres de gestação), obesos e imunossuprimidos. Entre esses grupos, varia de $0,2 \%$ a $20 \%$ o número de mortes atribuídas ao vírus Influenza (VERONESI; FOCACCIA, 2015). 
A infecção pelo vírus da gripe costuma ser reconhecida pelos seus sintomas típicos como febre alta e de início súbito, cefaleia, mialgia e coriza. Acomete, principalmente, as vias aéreas superiores, podendo se estender para suas regiões inferiores em casos mais extremos. Cerca de três a cinco milhões de indivíduos contraem a doença no mundo inteiro todos os anos, chegando a causar até meio milhão de mortes nesse mesmo período (OPAS, 2012).

Esse vírus possui algumas particularidades, podendo ser classificado como Influenza A, Influenza B e Influenza C, o primeiro relacionado a casos mais graves. Esse agente possui uma série de proteínas de membrana que são as principais responsáveis pela alta variabilidade genética desse vírus, fator que leva à dificuldade de uma proteção duradoura através de uma vacinação única (VERONESI; FOCACCIA, 2015). Além do fato de o vírus ter um curto período de incubação e transmitir-se por via aérea (facilitando sua disseminação), sua imunização é incapaz de gerar uma proteção cruzada, impossibilitando uma imunidade permanente.

O vírus da Influenza possui também uma grande facilidade de transmissão inter-humana, pelo fato de se transmitir por gotículas e penetrar no organismo humano pelas vias aéreas, possuindo, dessa maneira, grande taxa de ataque, ou seja, uma pessoa exposta ao agente muito provavelmente desenvolverá a doença (VERONESI; FOCACCIA, 2015). Outro fato preocupante são suas complicações, sendo a mais frequente a pneumonia (causada pelo próprio causador da gripe ou agentes secundários), que costuma ser responsável pela maioria das hospitalizações e mortes por essa doença (BRASIL, 2017a).

Com base nessas informações, dados epidemiológicos comprovam a gravidade dessa patologia nos últimos anos. Pois, a vigilância da Influenza e dos outros vírus respiratórios é realizada pela vigilância universal dos casos de Síndrome Respiratória Aguda Grave (possível complicação da infecção citada) dos internados e óbitos e pela vigilância sentinela (sendo essa última realizada por unidades de saúde que buscam identificar, investigar e notificar tais casos). No Brasil, até a semana epidemiológica (SE) 45 de 2017 foram notificados 20.521 casos e 2.935 óbitos por Síndrome respiratória Aguda Grave, o que corresponde a 14,3\% (2.935/20.521) do total de casos. Do total de óbitos notificados, $465(15,8 \%)$ foram confirmados para vírus influenza, sendo São Paulo o estado com o maior número de óbitos. (BRASIL, 2017c). Dessa forma, a taxa de mortalidade por influenza no Brasil até aquela SE chegou a 0,22/100.0oo habitantes (PARANÁ, 2017a).

Diante de tais fatos, a vacinação é uma das medidas mais eficazes para a prevenção das complicações do vírus da gripe, pois se estima que ela possa reduzir em até $45 \%$ o número de hospitalizações por pneumonia e em até $75 \%$ a morte em todo o mundo. Além de existir evidências que tal tipo de imunização seja capaz de reduzir o tempo de internação hospitalar dos acometidos pela enfermidade em cerca de dois dias (BRASIL, 2017b).

Essa vacina também faz parte do Programa Nacional de Imunizações (PNI), criado em 1973, depois de o Brasil acumular mais de 200 anos de imunizações, uma vez que as primeiras aplicações de vacina ocorreram no país em 1804. O PNI desenvolveu estratégias diversas, planejadas e sistematizadas como varreduras, campanhas e bloqueios que puderam controlar doenças como a poliomielite, difteria e coqueluche. Diante das respostas positivas a essas imunizações, mais recentemente foram implementadas vacinações contra Hepatite B, infecções pneumocócicas e também contra o vírus Influenza com suas campanhas anuais, reduzindo a quantidade de óbitos por doenças consideradas imunopreveníveis (BRASIL, 2003).

Um outro fator preocupante e de impacto sobre a vacinação da gripe é sua razão econômica, pois é sabido dos altos valores investidos nessas campanhas, visto que no ano de 2017, em seu segundo período, foram gastos mais de 34 milhões de reais na produção dos materiais publicitários da campanha, dos quais cerca de 200 mil foram destinados para pesquisa visando à sua elaboração. Seu maior investimento se deu no setor eletrônico em que foram despendidos mais de 23 milhões (BRASIL, 2018a). Além de mais de 99 
milhões gastos nas suas divulgações midiáticas no mesmo período citado, sendo disseminada por veículos impressos, televisão, rádio, entre outros meios de comunicação (BRASIL, 2018b).

Porém, mesmo já comprovada sua eficácia, e perante todos os esforços do Ministério da Saúde, as taxas de imunização ainda são preocupantes em determinados segmentos, visto que até a semana epidemiológica 32 de 2017, apenas quatro grupos do país possuíam cobertura vacinal acima da meta prevista para o ano, sendo esses os de puérperas (98,9\%), indígenas (94,31\%), idosos (94,25\%) e professores $(92,41 \%)$, totalizando mais de 22 milhões de pessoas que receberam a imunização. Já nos grupos de crianças de seis meses a cinco anos de idade, trabalhadores na área de saúde e gestantes, a cobertura ficou abaixo da meta prevista, correspondendo a $76,75 \%, 87,71 \%$ e 77,66\%, respectivamente. Considerando a vacinação de todos os grupos juntos, 38.362 .662 pessoas foram vacinadas, o que corresponde a 87,24 \% dos grupos prioritários, uma proporção também abaixo do que estava previsto (BRASIL, 2017b).

A campanha de vacinação contra Influenza desenvolvida no ano de 2017 teve como objetivos reduzir internações, hospitalizações e mortes causadas por esse agente, elegendo como público-alvo: crianças de seis meses a cinco anos, pessoas com mais de 60 anos, gestantes, puérperas, trabalhadores de saúde entres outros grupos também considerados de risco. Essa campanha possuiu meta de vacinação de $90 \%$ de cada grupo formado pelas populações prioritárias e, para receber a imunização, era necessário apenas se dirigir a um posto de vacinação, sendo a vacina gratuita e distribuída em todo território nacional (BRASIL, 2017a).

\section{ESTRATÉGIA METODOLÓGICA}

Trata-se de uma pesquisa do tipo qualitativa e documental, e consiste na análise de conteúdos veiculados em materiais elaborados pelo Ministério da Saúde no Brasil com o objetivo de promover a conscientização nacional sobre a importância da vacinação contra a Influenza

A metodologia é entendida como o caminho a ser seguido pelo pesquisador para conseguir abordar a realidade. Dessa forma, ocupa local central no interior das teorias sociais, devido ao fato de fazer parte da visão social de mundo vinculada à teoria. O modo qualitativo se aplica principalmente a estudos menos exatos e mais interpretativos, que buscam entender como o ser humano se relaciona com o meio em que vive e entre si. De tal maneira, sua natureza menos enclausurada permite que o investigador consiga validar ou invalidar hipóteses, com a vantagem de conseguir dar uma maior relevância às questões que mais necessitarem conforme suas descobertas (MINAYO, 2014).

Considera-se o trabalho que fundamenta este artigo como pesquisa documental tendo em vista o que Sá-Silva, Almeida e Guindani (2009) classificaram como documento e pesquisa documental. Para esses autores, ela utiliza os mesmos princípios da pesquisa bibliográfica e consiste em extrair as informações dos documentos. Dessa forma, o segundo aspecto a ser considerado consiste em definir o que é um documento e por que esta investigação é documental. Uma pesquisa bibliográfica vai diretamente às fontes secundárias, ou seja, a resultados de análises já elaboradas, enquanto a análise documental concentra-se em fontes primárias, que ainda não receberam tratamento analítico. O material aqui analisado pertence a esta última categoria porque dados textuais ou figurais foram analisados diretamente do material primário produzido pelo Ministério da Saúde no Brasil, não tendo recebido nenhuma análise ou tratamento anterior.

Segundo a perspectiva educativa desenvolvida por Zabala (1998), os conteúdos de ensino podem ser classificados em quatro categorias que expressam os valores atribuídos ao ensino e ao que se deve aprender. Essas categorias estão relacionadas a: conteúdos factuais, conteúdos conceituais, conteúdos procedimentais e conteúdos atitudinais. Essa divisão é utilizada principalmente para avaliação do processo de aprendizagem e, no caso aqui abordado, foi utilizada com o intuito de mensurar a abrangência cognitiva das campanhas de conscientização sobre a vacinação contra a Influenza. 
O primeiro tipo de conteúdo descrito foi o factual, geralmente utilizado quando se deseja que alguém domine uma informação de modo que, quando questionada, saiba informar com o máximo de exatidão a resposta ao questionamento; esses conteúdos dizem respeito, por exemplo, ao conhecimento de fatos como episódios históricos, nomes de objetos e acidentes geográficos. Porém, para que se possa afirmar que de fato ocorreu o aprendizado, os fatos não podem permanecer no nível da memorização de acontecimentos e nomes pontuais, mais sim é preciso avançar no sentido de compreender o contexto que os envolve (ZABALA, 1998). Exemplificando: uma aprendizagem significativa, na perspectiva desse autor, não é apenas saber que Mato Grosso do Sul é um estado brasileiro, mas perceber que ele está inserido em uma série de outras esferas relevantes. Que ele está localizado na região Centro-Oeste e sua capital é Campo Grande. Dessa forma, o conhecimento de um conteúdo factual é condição necessária para que um conceito seja construído, mas em si ele é insuficiente. No caso específico da educação em saúde, é importante que a população saiba que existe um vírus causador da Influenza e que há uma vacina preventiva, mas essas informações factuais não são suficientes para que ocorra uma mobilização em busca da proteção. Datas de vacinação são facilmente esquecíveis e os nomes dos vírus nem sempre são divulgados, dada a relevância desse fato apenas para alguns. Informações epidemiológicas são fatos que podem impactar porque estão ligados ao bem-estar, à segurança da família. Essa complementação de informações e contextualização pode elevar o nível de aprendizado daquele que está lendo e a uma possível mudança em sua forma de pensar e agir diante de um chamado à vacinação.

São relevantes também questões como: O que é Influenza? Que males causa? Por que deve uma pessoa ser vacinada? O que significa ser vacinado? Essas questões pertencem ao campo dos conceitos e das atitudes.

O conteúdo conceitual é o objetivo da aprendizagem. De uma aprendizagem que começa com o domínio de informações factuais e, em seguida, passa para um grau maior de complexidade. Conceitos são conteúdos amplos e construídos a partir de fatos e procedimentos. É um tipo de conteúdo que envolve a compreensão de seu interlocutor e não apenas uma memorização de dados prontos (ZABALA, 1998). Influenza é um conceito bem como a sua relação com o bem-estar pessoal e familiar. E um conhecimento que permite extrapolar a simples ligação com um fato em particular e verificar a real assimilação do receptor de informações. Segundo o Ministério da Saúde, influenza é uma infecção viral aguda do sistema respiratório, de elevada transmissibilidade e distribuição global. Um indivíduo pode contraí-la várias vezes ao longo da vida. Em geral, tem evolução autolimitada, podendo, contudo, apresentar-se de forma grave (BRASIL, 201-) e é responsável por um grande número de internações hospitalares. Nessa transmissibilidade e possibilidade de agravamento do quadro infeccioso está a necessidade de conscientização da população sobre os seus efeitos.

Para Zabala (1998), tantos os conteúdos factuais quanto conceituais são modos de se ter conhecimento que ficam apenas armazenados no cérebro daqueles que adquiriram essas informações. Um modo mais profundo de conhecimento é quando o indivíduo consegue aplicar esse saber, ou seja, realizar atividades práticas que o apliquem. O conteúdo procedimental visa justamente à avaliação dessas ações, ou seja, implica executar o aprendido. Os verbos no infinitivo normalmente indicam procedimentos e pode-se dizer que se proteger e proteger a família contra a Influenza por meio da vacinação é tanto um procedimento quanto uma atitude. É procedimento enquanto ato momentâneo e é atitude enquanto ação duradoura. Um procedimento pode ser resultado de uma atitude ou de uma pressão social específica. Nesse último caso perdeu seu componente atitudinal.

Por último, segundo Zabala (1998), os conteúdos atitudinais são os mais difíceis de avaliar quando se analisa uma população, pois esse depende de uma série de componentes individuais, sendo eles os aspectos cognitivos, as condutas e a afeição. Esse tipo de conhecimento, diferente dos descritos anteriormente, não prioriza a memorização, mas sim a autonomia do indivíduo no que diz respeito à maneira como o 
conhecimento adquirido pode interferir no seu cotidiano. Por exemplo, se alguém sabe que a vacina contra a gripe é aplicada durante determinado período do ano, tem um conhecimento factual. Se agenda essa vacinação ou se desloca até o local para que isso ocorra, é um procedimento. Porém, tal procedimento pode não ir além de um ato isolado ou ser resultado da pressão social impressa pela propaganda maciça do momento. No entanto, pode ser resultado de uma consciência de autoproteção e busca de bem-estar o que faz com que essa pessoa esteja atenta às oportunidades de livrar-se dos incômodos decorrentes de um possível contágio. Neste caso, trata-se de uma atitude, do resultado da construção de valores relativos à sua vida e à vida de outros. É um procedimento que reflete uma atitude.

Dessa forma, a função social do ensino não é apenas promover ou selecionar determinados indivíduos considerados mais aptos para determinada prova ou função, mas levá-los a ter uma formação integral. Ou seja, contribuir para o desenvolvimento de todas as suas capacidades de compreensão e aprendizagem de todos os tipos de conteúdos incluindo a construção de conceitos e atitudes. Tendo como exemplo a campanha de vacinação, cuja análise é o objetivo deste trabalho, é necessário que se tenha o conhecimento de fatos, como data da vacinação, de conceitos, como o de imunização para que esse entenda sua importância, informações que favoreçam procedimentos como se locomover até o posto de vacinação e apelo à valorização da saúde para que o indivíduo realize suas ações devido a uma conscientização e não por uma pressão social (ZABALA, 1998).

Para esta análise, foram escolhidos materiais disponibilizados pelo Ministério da Saúde no Brasil para a campanha de combate à gripe. Durante o desenvolvimento deste trabalho, alguns dos arquivos disponibilizados foram excluídos, como os audiovisuais e os áudios para facilitar a análise. Assim, entre as opções dos materiais visuais foi escolhido um representante da campanha, no caso, a imagem do ano de 2016, por sua concisão.

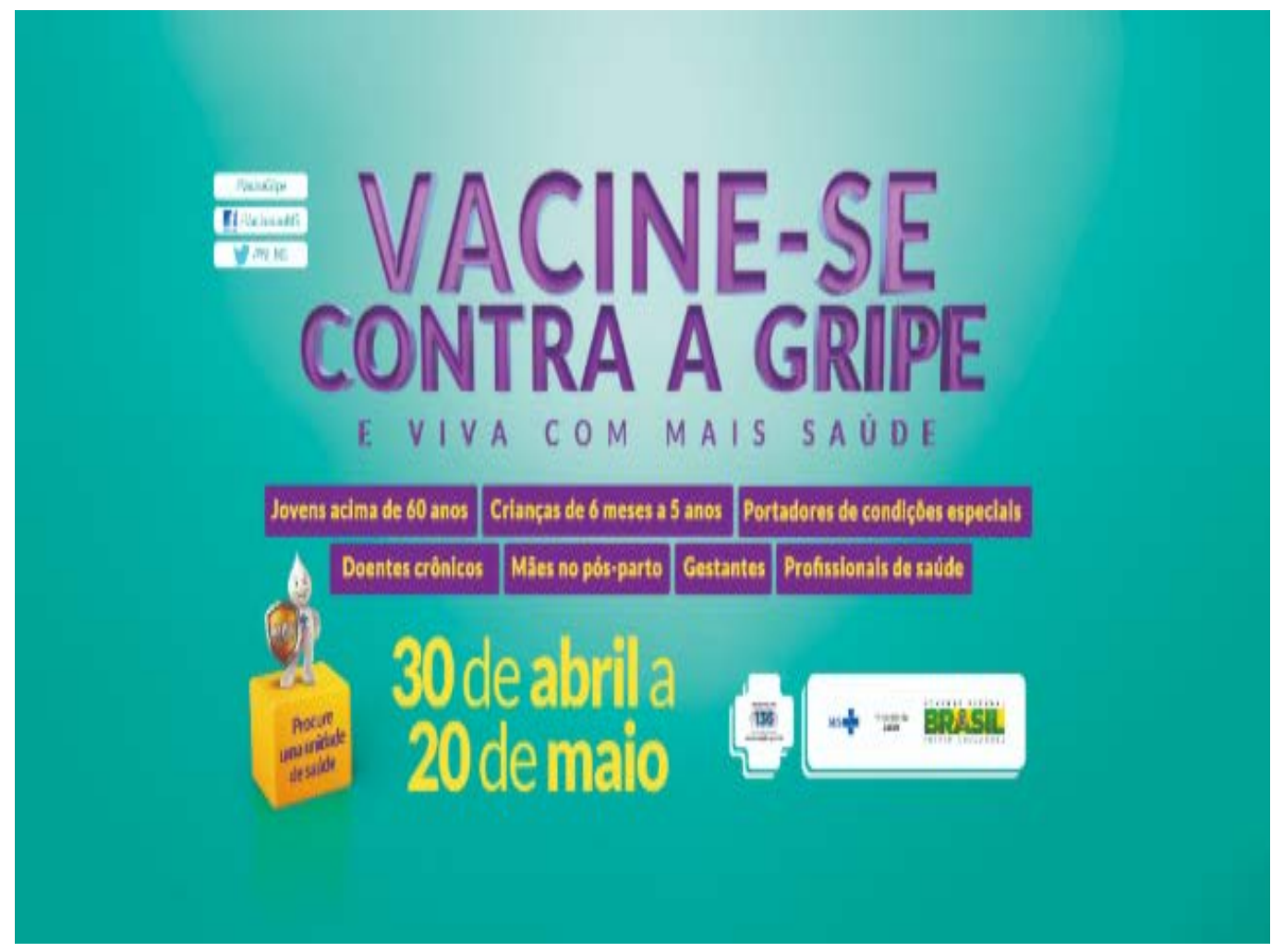

Figura 1 - Imagem utilizada na campanha de vacinação contra Influenza de 2016 Fonte: BRASIL, 2016. 


\section{RESULTADOS}

Os materiais impressos utilizados nas campanhas de conscientização sobre a vacina contra Influenza visam divulgar informações relevantes para seu público-alvo, de modo a conscientizá-lo, sendo o conteúdo veiculado por eles o seu principal propósito.

O material utilizado na campanha aqui analisada foi veiculado no site "Blog da saúde" do Ministério da Saúde no dia 3 de maio de 2016. Esse material não teve suas dimensões divulgadas, contendo apenas uma face com uma imagem (ver Figura 1) descrita no Quadro 1.

\section{Quadro 1-Descrição da imagem da campanha de vacinação de 2016 contra Influenza}

\begin{tabular}{|c|c|c|}
\hline Enunciado & Tipo de conteúdo & Justificativa \\
\hline $\begin{array}{l}\text { Vacine-se contra a gripe e viva com } \\
\text { mais saúde }\end{array}$ & Procedimental, atitudinal & $\begin{array}{l}\text { Visa induzir o interlocutor ao } \\
\text { procedimento de ir receber a } \\
\text { imunização, utilizando-se do recurso } \\
\text { de que isto o levaria a uma vida mais } \\
\text { saudável. Tem ainda o objetivo de } \\
\text { induzir a atitude de valorização da } \\
\text { saúde. }\end{array}$ \\
\hline $\begin{array}{l}\text { Jovens acima de } 60 \text { anos, crianças } \\
\text { de } 6 \text { meses a } 5 \text { anos, portadores } \\
\text { de condições especiais, doentes } \\
\text { crônicos, mães no pós-parto, } \\
\text { gestantes, profissionais da saúde }\end{array}$ & Factual, conceitual & $\begin{array}{l}\text { Mostra o fato já confirmado que é } \\
\text { a vulnerabilidade de certos grupos } \\
\text { que por diferentes motivos precisam } \\
\text { de imunização, introduzindo de } \\
\text { modo implícito o seu conceito de } \\
\text { vulnerabilidade ou fragilidade diante da } \\
\text { influenza }\end{array}$ \\
\hline Vacinar é proteger & Factual & $\begin{array}{l}\text { Mostra o fato comprovado que vacina é } \\
\text { proteção }\end{array}$ \\
\hline Procure uma unidade de saúde & Procedimental, atitudinal & $\begin{array}{l}\text { Procura induzir o leitor a adotar o } \\
\text { procedimento de se locomover até a } \\
\text { unidade de vacinação para receber } \\
\text { sua imunização. A atitude de buscar a } \\
\text { proteção da vacina, é também induzida } \\
\text { por esse material. }\end{array}$ \\
\hline $\begin{array}{l}30 \text { de abril a } 20 \text { de maio } \\
\text { (data da vacinação) }\end{array}$ & Factual & Anuncia um fato. \\
\hline
\end{tabular}

Fonte: elaboração dos autores.

\section{DISCUSSÃO}

Na imagem analisada, como se pode observar, há um total de oito conteúdos que dificilmente são utilizados de maneira isolada e são distribuídos ao longo de cinco enunciados. Houve predomínio dos conteúdos atitudinais e procedimentais que são usados de maneira conjunta em detrimento do conteúdo conceitual que é utilizado e aparece uma única vez. Dessa forma, nota-se que os esforços do Ministério da Saúde no ano de 2016 se concentraram apenas em transmitir informações, dando ênfase a conteúdos factuais como 'vacinar é proteger', mas não dando um embasamento mais sólido a essa informação, devido à escassa quantidade de conteúdos conceituais. Assim sendo, o leitor sentirá dificuldade de se convencer por meio dos conteúdos seguintes, pois, por serem procedimentais e buscarem mostrar, para aquele que lê o material, como executar as ações necessárias para receber a imunização, deveriam propiciar uma compreensão completa para que possibilitassem atitudes e viessem a acontecer. Da forma como está colocado, o procedimento poderá permanecer no nível mecânico. 


\section{CONCLUSÃO}

Em uma sociedade globalizada, com fácil acesso à informação e grande capacidade de disseminar doenças, os mitos em torno das imunizações ainda preocupam, considerando uma necessidade de vacinação que aumenta conforme o tempo. Em razão disso, há urgência de elaboração de materiais educativos e de publicidade para que a imunização atinja proporções adequadas. Dessa forma, os esforços do Ministério da Saúde junto a outras esferas governamentais mostram-se importantes fatores de popularização de recursos, principalmente visuais, a diferentes populações do país.

A imagem analisada carrega a frase 'Vacinar é proteger', e tal fato não busca apenas ser meramente ilustrativo, mas mostrar que a vacinação precisa estar à frente, ou seja, antes, daquele que deseja receber a imunização efetiva e assim ser protegido. Todavia, esse é praticamente o único recurso não verbal usado na ilustração, podendo dificultar a passagem dessa informação àqueles com menor escolaridade. É interessante destacar também o predomínio de conteúdos procedimentais e atitudinais em detrimento dos outros, fato, como já destacado, que compromete o real engajamento do leitor na vacinação e pode comprometer a imunização coletiva por parte dos leitores mais indagadores. Dessa forma, o material elaborado pelo Ministério da Saúde é considerado apto a transmitir informações, como data da vacinação e seu local, porém não é capaz de levar à conscientização do leitor, o que pode refletir nos números de cobertura vacinal a longo prazo.

\section{REFERÊNCIAS}

BRASIL. Lei № 1.261, de 31 de outubro de 1904. Torna obrigatórias, em toda República, a vaccinação e a revaccinação contra a varíola. Diário Oficial da União, Brasília, DF, 2 nov. 1904. Seção 1, p. 5158.

BRASIL. Ministério da saúde. Publicação dos valores pagos no período de 01/07/2017 a 31/12/2017. [Brasília, DF; Ministério da Saúde], 2018a. Disponível em: http://portalarquivos2.saude.gov.br/images/ pdf/2018/maio/25/2017-2sem-producao.pdf. Acesso em: 30 out. 2018.

BRASIL. Ministério da Saúde. Publicação dos valores pagos no período de 01/07/2017 a 31/12/2017. [Brasília, DF; Ministério da Saúde], 2018b. Disponível em: http://portalarquivos.saude.gov.br/images/ pdf/2018/maio/25/2017-2sem-midia.pdf. Acesso em: 30 out. 2018.

BRASIL. Ministério da Saúde. Saúde Brasil contra a Influenza. [Brasília, DF: Ministério da Saúde, 201-] Disponível em: https://saudebrasil.saude.gov.br/saude-brasil-contra-a-influenza. Acesso em: 11 nov. 2018.

BRASIL. Ministério da Saúde. Vacinação contra a gripe: entenda se você faz parte do grupo prioritário. In: BRASIL. Ministério da Saúde. Blog do Ministério da Saúde. [Brasília, DF], 03 maio 2016. Disponível em: http://www.blog.saude.gov.br/entenda-o-sus/50930-vacinacao-contra-a-gripe-entenda-se-voce-faz-partedo-grupo-prioritariohtml.html. Acesso em: $27 \mathrm{dez} .2018$.

BRASIL. Ministério da Saúde. Secretaria de Vigilância Sanitária. 19a Campanha Nacional de Vacinação contra a Influenza. Brasília, DF: Secretaria de Vigilância Sanitária, 2017a. Informe Técnico. Disponível em: http://pni.datasus.gov.br/sipni/03\%2003\%202017\%20Informe Cp Influenza\%20 \%20final.pdf. Acesso em: 30 ago. 2018.

BRASIL. Ministério da Saúde. Secretaria de Vigilância em Saúde. Situação epidemiológica no Brasil, até a Semana Epidemiológica 32 de 2017. Boletim epidemiológico, [Brasília, DF], v. 48, n. 25, p. 1-11, 2017b. Disponível em: http://portalarquivos2.saude.gov.br/images/pdf/2017/agosto/21/2017 023-SituacaoEpidemiologica-da-Influenza-no-Brasil-ate-a-Semana-Epidemiologica-32-de-2017.pdf. Acesso em: 10 set. 2018.

BRASIL. Ministério da Saúde. Secretaria de Vigilância em Saúde. Influenza: Monitoramento até a Semana Epidemiológica 45 de 2017. Informe Epidemiológico, n. 45, Brasília, DF: Secretaria de Vigilância em Saúde, 2017c. Disponível em: https://portalarquivos2.saude.gov.br/images/pdf/2017/novembro/20/InformeEpidemiol--gico-Influenza-2017-SE-45.pdf. Acesso em: 10 set. 2018. 
FORLEO-NETO, Eduardo; HALKER, Elisa; SANTOS, Verônica Jorge; PAIVA, Terezinha Maria; TONIOLONETO, João. Influenza. Revista da Sociedade Brasileira de Medicina Tropical, Uberaba, v. 36, n. 2, p. $267-$ 274, mar./abr. 2003. Disponível em: http://www.scielo.br/pdf/rsbmt/v36n2/a11v36n2.pdf. Acesso em: 11 set. 2019.

FUNDAÇÃO OSWALDO CRUZ (FIOCRUZ). Como surgiram as vacinas?. Rio de Janeiro: Instituto de Tecnologia em Imunobiológicos (Bio-Manguinhos), 2010. Disponível em: https://www.bio.fiocruz.br/index.php/ perguntas-frequentes/69-perguntas-frequentes/perguntas-frequentes-vacinas/213-como-surgiram-asvacinas. Acesso em: 20 jan. 2019.

GILIO, Alfredo. A importância da vacinação. São Paulo: Hospital Israelita Albert Einstein, 2017. Disponível em: https://www.einstein.br/noticias/noticia/a-importancia-da-vacinacao. Acesso em: 20 jan. 2019.

MINAYO, Maria Cecília de Souza. O desafio do conhecimento: pesquisa qualitativa em saúde. 14. ed. São Paulo: Hucitec, 2014.

ORGANIZAÇÃO PAN-AMERICANA DE SAÚDE (OPAS). Boletim informativo: SVS - Influenza (Gripe) Semana epidemiológica (SE) 32. [Brasília, DF: Secretaria de Vigilância em Saúde, 2012]. Disponível em: https://www.paho.org/bra/index.php?option=com content\&view=article\&id=2970:boletim-informativo-svsinfluenza-gripe-semana-epidemiologica-se-32\&ltemid=463. Acesso em: 13 set. 2018.

PARANÁ. Secretaria de Estado da Saúde. Superintendência de Vigilância em Saúde. Centro de Epidemiologia. Divisão de Vigilância das Doenças Transmissíveis. Informe Epidemiológico da Vigilância da Influenza ${ }^{\circ}$ 22/2017 (atualizado em nov. 2017). 2017 Disponível em: http://www.saude.pr.gov.br/arquivos/ File/Informelnflu22 2017 .pdf. Acesso em: 30 ago. 2018.

RIO DE JANEIRO (Cidade). Secretaria Especial de Comunicação Social. 1904 - Revolta da Vacina: a maior batalha do Rio. Rio de Janeiro: Prefeitura do Rio de Janeiro, 2006. (Cadernos da Comunicação Série Memória). Disponível em: http://www.rio.ri.gov.br/dlstatic/10112/4204434/4101424/memoria16.pdf. Acesso em: 20 out. 2018.

SÁ-SILVA, Jackson Ronie; ALMEIDA, Cristóvão Domingos de; GUINDANI, Joel Felipe. Pesquisa documental: pistas teóricas e metodológicas. Revista Brasileira de História \& Ciências Sociais, Porto Alegre, v. 1, n. 1, p. 1- 15, jul. 2009. Disponível em: https://periodicos.furg.br/rbhcs/article/view/10351. Acesso em: 22 out. 2018.

SMITH, Philip J.; CHU, Susan Y.; BARKER, Lawrence E. Children who have received no vaccines: who are they and where do they live?. Pediatrics, Springfield, v. 114, n. 1, p. 187-195, jul. 2004. DOI: https://doi. org/10.1542/peds.114.1.187. Disponível em: https://pubmed.ncbi.nlm.nih.gov/15231927/. Acesso em: 22 out. 2018 .

SOUZA, Patrícia Melo e. A Revolta da Vacina. In: FUNDAÇÃO BIBLIOTECA NACIONAL. Rede da memória virtual brasileira. Rio de Janeiro, 2006. Disponível em: https://bndigital.bn.gov.br/dossies/rede-da-memoriavirtual-brasileira/politica/a-revolta-da-vacinal. Acesso em: 22 out. 2018.

VERONESI, Ricardo; FOCACCIA, Roberto. Tratado de infectologia. 5. ed. Rio de Janeiro: Atheneu, 2015.

ZABALA, Antoni. A prática educativa: como ensinar. Porto Alegre: Artes Médicas Sul, 1998. 